\title{
An innovative fixture for testing the crashworthiness of composite materials
}

\author{
Lorenzo Vigna, Iman Babaei, Ravin Garg, Giovanni Belingardi, Davide Salvatore Paolino \\ Department of Mechanical and Aerospace Engineering, Politecnico di Torino, Italy \\ lorenzo_vigna@polito.it, bttps://orcid.org/0000-0002-5913-253X \\ iman.babaei@polito.it, https://orcid.org/0000-0002-6471-5094 \\ ravin.garg@polito.it, bttps://orcid.org/0000-0001-5473-7436 \\ giovanni.belingardi@polito.it, https:/ /orcid.org/0000-0003-1378-1902 \\ davide.paolino@polito.it, https://orcid.org/0000-0002-4231-4580
}

Andrea Calzolari, Giuseppe Galizia
ITW Test and Measurement Italy, Italy
andrea_calzolari@instron.com, https:// orcid.org/0000-0002-2605-7203
giuseppe_galizia@instron.com, bttps:/ / orcid.org/0000-0002-9837-286X

ABSTRACT. Despite the growing diffusion of composite materials in automotive and aerospace sectors, a standard procedure for testing their crashworthiness has not been developed yet. At present, the international standards for testing composite materials under impact conditions are not adequate to test their crush behavior.

In this paper, a procedure for measuring the energy absorption due to the compressive crushing of a composite flat specimen along its mid plane is proposed. The experimental setup requires a fixture to hold the specimen and to avoid its buckling and an instrumented drop weight tower to obtain the force-displacement curves with the aim of calculating the Specific Energy Absorption.

The paper describes the adopted test procedure and some of the features of the newly developed experimental setup. The effectiveness of the procedure is demonstrated by testing several glass fiber-epoxy specimens under different impact energies.

KEYwORDS. Crashworthiness; Specific Energy Absorption; Impact response.

\section{INTRODUCTION}

$\mathrm{T}$ he growing diffusion of composite materials in the automotive and aerospace sectors is mainly due to the excellent mechanical properties combined with low density. Other features like the possibility to design the material properties choosing the right combination of matrixes, fibers, curing cycles and manufacturing processes have made composites the best choice for those applications where high performances are needed. 
The numerous studies carried out in last decades have built up a wide knowledge of composite materials, of their properties and of the manufacturing processes. Today this knowledge makes the design process of a composite structure quite easy, also thanks to the numerous tools and software that can be used for the design. Nevertheless, the crashworthiness of composite materials is a field in which the research is still evolving due to the difficulty of prediction of the failure of a composite structure during crash and to the absence of a standard test method for the characterization of the Specific Energy Absorption (SEA) [1].

The term "crashworthiness" provides a measure of the ability of a structure to protect the occupants in survivable crashes. When an impact occurs, structures must deform irreversibly in a short period of time (milliseconds) to absorb the crash energy in a controllable manner. The typical strategy to achieve this objective is to include in the chassis of the vehicle some elements specifically designed to absorb a large part of the kinetic energy in a controlled way [2].

The components designed as crash absorbers are typically made of ductile metals, that can absorb a high quantity of energy before their final failure. The prediction of the behavior of this kind of structure is quite easy with current simulation algorithms, that allow to model the damage progression of metals with good accuracy.

It is well-known in the literature that composite materials have good energy absorption capabilities and offer even better performance than metals in terms of specific energy absorption [3]. However, the simulation of the crash phenomenon in composite materials is extremely difficult because several failure mechanisms can occur, and each of them has a proper efficiency in terms of energy absorption [4].

There are several factors that can influence the failure mechanisms, such as the geometry, the matrix and the fibers utilized, the layup design and the manufacturing process. The failure modes can be subdivided in some categories, even if a proper categorization with widely accepted nomenclature has not yet been developed. The main studies on the failure modes of composites under crash have been carried out by Farley and Jones [4] and Hull [5], that have divided the failure modes in four main categories:

- tearing or transverse shearing with crack growth inside the fabric layer, causing the rupture of both matrix and fibers

- $\quad$ splaying, lamina bending or foiling, characterized by the separation of two layers of the laminate that bend in two opposite directions. The energy is mostly dissipated in matrix breaking due to the delamination

- brittle fracturing or fragmentation that causes the formation of small fragments and cracks inside the fiber's fabric

- local buckling or progressive folding characterized by the local bending of the structure, similar to what happens during plastic folding of ductile metals.

A composite structure subjected to crash usually involves a combination of failure modes, and it is difficult to foresee which failure mode will occur in a structure before performing a test. Furthermore, every failure mechanism has a proper capability to absorb energy through deformation and rupture. A more detailed description of the failure modes of composite materials can be found in the literature [4,5].

Several studies have been carried out to predict through numerical simulations the crash behavior of complex composite components but, at present, there are no standard experimental procedures available in the literature [6-10]. The availability of a standard testing procedure to assess the material properties required by material cards used in simulation software would certainly increase the efficiency of the design process and reduce the related costs.

Focusing on impact tests, existing standards like the puncture tests (ASTM D3763 [11], ASTM D5628 [12], ISO 6603 $[13,14]$ ) and the Compression After Impact test (ASTM D7136 [15] and D7137 [16], ISO 18325 [17]) are not adequate to provide a measure of the crashworthiness of the material. Indeed, in the available standards, impact loads are applied in the direction perpendicular to the laminate plane (out-of-plane loading condition) and not parallel to the plane (in-plane loading condition), as it typically occurs on crash absorbers during crash events.

In long fiber composite materials subjected to crash the most typical failure modes are tearing and splaying. The splaying failure mode is typical of parts designed as crash absorbers. These components usually have a tube or a box-like geometry to avoid buckling and to guarantee a certain length of crushable material and are widely used in automotive and aerospace sectors. While some tearing can occur in small areas of these components when subjected to crash, most of the material shows delamination according to the splaying failure mode.

For this reason, the study of the splaying is of particular interest. Several studies have been carried out in the past 30 years to measure the energy absorption of plain composite specimens, that can easily show splaying if their buckling is avoided through a proper testing fixture. The design of the fixture is extremely important to obtain the desired failure mode of the specimen.

The first fixture designed to test the crashworthiness of composite flat specimens was developed by NASA in the early 90 's [18]. This fixture was made of four vertical columns acting as anti-buckling system, and two horizontal plates through which the load was applied to the specimen. The load-displacement curves obtained were similar to those measured with samples 
of different shapes, like tubes and cones. However, the specific energy absorption was higher than expected because of the over-constraint of the specimen provided by the anti-buckling system.

Several fixtures were developed in the following years to overcome the problems raised by the NASA fixture. One of the most interesting was built by Feraboli [19]. With this fixture in 2009 several carbon fiber specimens were successfully crashed under quasi static load, obtaining the desired failure mode. The key element of this fixture is the anti-buckling system: it maintains a part of the specimen unsupported, decreasing the constraining effect of the fixture and leaving enough space to crush and eliminate the debris. The results obtained from flat specimens were also compared with those obtained from complex shape elements like square and L-shape elements that give different failure modes. A relation was found between curvature and specific energy absorption [20].

An interesting progress in the field of crashworthiness of composite materials has been proposed by the company Engenuity [21]. It consists of an experimental setup similar to that of Feraboli, but with the addition of some features able to induce other failure modes in the specimen (such as tearing) if desired. Engenuity worked as well on the simulation software to predict the crush behavior of structures, getting good agreement with experimental tests [21]. The Engenuity's fixture was successfully used under dynamic and impact load [22].

Other researchers have designed similar devices for testing flat specimens with good results both in quasi-static and dynamic load conditions, showing the effectiveness of using a plane specimen to characterize the material [23-26]. Nevertheless, none of the reported testing setups is considered as a standard for the measurement of the SEA.

The present paper reports the design of an innovative fixture for testing the crashworthiness of flat composite specimens under dynamic load. The device is designed to be fully integrated in a drop tower testing system to replicate the dynamic effects that occur during a crash, that only few studies have addressed using a flat specimen [10,22,24]. The work represents a first step in the process of defining a standard testing procedure for the assessment of crash properties of composite materials through in-plane impact loads.

\section{EXPERIMENTAL SETUP AND TESTING PROCEDURE}

$\mathrm{T}$

he aim of the present testing procedure is to measure the crushing force and the absorbed energy of a plane composite specimen. This allows to calculate the Specific Energy Absorption (SEA), which is commonly used as an indicator of the specific amount of energy that the material can absorb during a crash event:

$$
S E A=\frac{E}{\rho A \delta}=\frac{\int F d x}{\rho A \delta},
$$

where $E$ is the energy absorbed during the crash event, $\rho$ is the density of the material, $A$ is the cross section of the specimen, $\delta$ is the length of the crushed part of the specimen, and $F$ is the force measured during the crash.

The crash event should be obtained through an appropriate equipment in order to get the desired failure mode under the required load condition. For the present tests, the load is applied as a falling weight of known mass and velocity, dropped by a drop tower.

All tests have been carried out in an Instron 9450 drop weight tower, using an instrumented striker equipped with a $222 \mathrm{kN}$ load cell and an acquisition system operating with a sampling frequency of $1 \mathrm{MHz}$. All tests have been performed using a total falling mass of $60.2 \mathrm{~kg}$ and potential energy varying from $400 \mathrm{~J}$ to $700 \mathrm{~J}$, obtained through different drop heights.

With this equipment it is possible to acquire a time-force curve and calculate the displacement of the falling mass by double integration of the force signal with respect to time. The calculation is numerically performed by the acquisition system according to:

$$
\delta(t)=\delta_{0}+v_{0} t+\frac{g t^{2}}{2}-\int_{0}^{t}\left(\int_{0}^{t} \frac{F(t)}{m} d t\right) d t,
$$

where $\delta_{0}$ and $v_{0}$ are the initial displacement and velocity, $t$ is the time, $m$ is the falling mass and $g$ the acceleration of gravity. From the displacement-force signal is then possible to obtain the energy absorbed during the crushing of the specimen. The tests were recorded using a Photron FASTCAM Mini AX high speed camera with a resolution of 1024x1024 pixels at $6400 \mathrm{fps}$ to observe the failure mode(s) and track the displacement of the specimen during the test. 


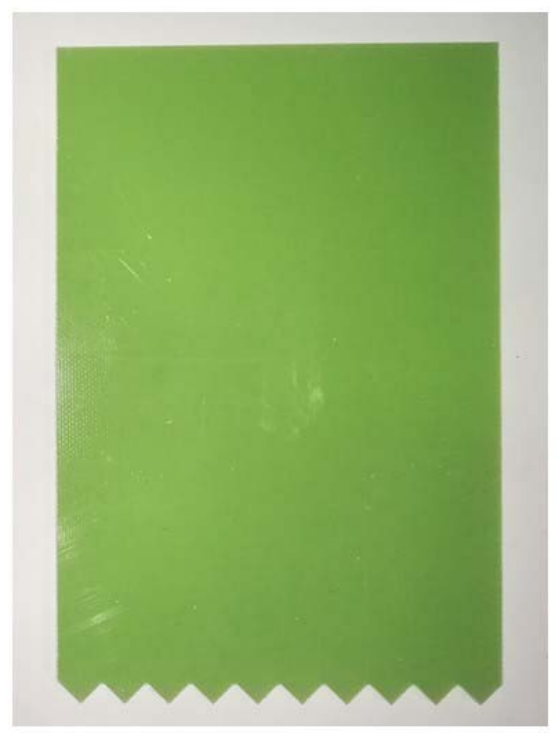

(a)

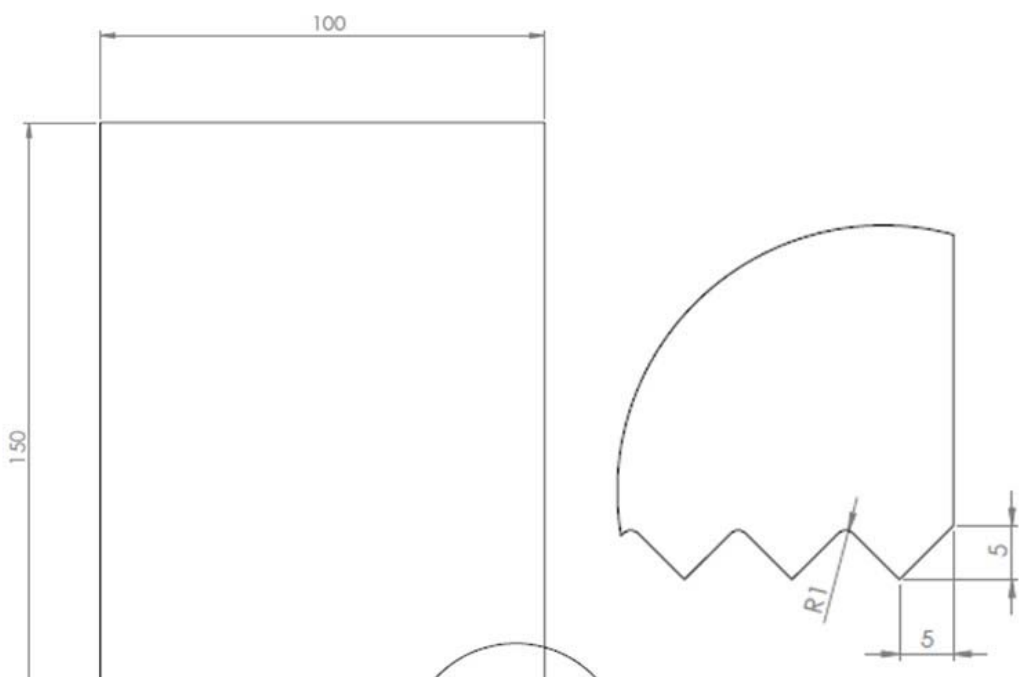

(c)

(b)

Figure 1: Glass fiber plain specimen for crashworthiness test (dimensions in $\mathrm{mm}$ ): (a) picture of the specimen, (b) overall dimensions of the specimen, (c) detail of the trigger geometry.

\section{Material}

Tests have been carried out on specimens made of glass fiber woven coated with epoxy resin. The material is a NEMA FR4 laminate with thickness of $3 \mathrm{~mm}$, made of a $0^{\circ} / 90^{\circ}$ glass fiber fabric coated with epoxy resin according to the standard NEMA LI-1 [27]. The fiber content is $60 \%$ in weight. It is a widely used material with the mechanical properties listed in Tab. 1. A flat specimen was chosen because considered to be the best choice to obtain delamination without occurring in other failure modes like tearing. A flat specimen is also low-cost and easy to manufacture.

The chosen dimensions of the plate are the same used for the Compression After Impact test (ASTM D7136 [15] and D7137 [16]), i.e. a rectangular plate with dimensions $150 \mathrm{~mm}$ and $100 \mathrm{~mm}$ (Fig. 1b).

A trigger feature is machined on one of the shorter sides in order to initiate the progressive crush of the specimen. A sawtooth trigger is chosen to correctly initiate the delamination in the desired part of the specimen (Fig. 1) and combined with the flat shape of the specimen selected to avoid undesired failure modes like tearing or buckling.

\begin{tabular}{cc}
\hline \multicolumn{1}{c}{ NEMA FR4 } \\
Density & $2.07 \mathrm{~kg} / \mathrm{dm}^{3}$ \\
Elastic modulus (ISO 178) & $24 \mathrm{GPa}$ \\
Tensile strength (ISO 527) & $300 \mathrm{MPa}$ \\
Flexure strength (ISO 178) & $500 \mathrm{MPa}$ \\
Compressive strength parallel to laminate (ISO 604) & $350 \mathrm{MPa}$ \\
Compressive strength perpendicular to laminate (ISO 604) & $500 \mathrm{MPa}$
\end{tabular}

Table 1: Mechanical properties of NEMA FR4 laminates. The density was measured by the authors, while the other properties are given by the supplier of the material [28].

\section{Fixture}

To avoid buckling, it has been decided to use lateral supports that permit to have a long enough crushable length. The designed anti-buckling fixture (Figs. 2a and 2b) consists of four vertical columns that, if sustained by a sufficiently stiff 
structure, completely avoid the buckling of the specimen [19]. The columns leave an unsupported height in the lower part of the specimen, where the failure takes place, to avoid over-constraining of the specimen and to leave enough space to remove debris and foils. The specimen must be positioned with the trigger in the lower part in order to have the initiation of the failure in the unsupported part. The unsupported height is constant during the test, but it can be modified to get different testing configurations.

The columns are connected to the lower part of the fixture trough an aluminum structure. The lateral stiffness required to avoid the buckling of the specimen is given by the structure that surrounds the specimen, whose parts are connected using four screws. A certain care should be taken when fastening the screws not to have too much friction between the specimen and the supporting columns, resulting in an overestimation of the crush force. In all tests the four screws have been fastened with a $1 \mathrm{Nm}$ torque, which is the lowest torque capable to provide enough lateral stiffness: in tests with lower values of torque, whose results are not reported in this paper, the specimen showed lateral oscillations due to presence of a clearance between the specimen and the anti-buckling columns.

Another critical feature of the support consists of the way the load is transmitted to the specimen. The fixture has been designed to allow two possible configurations. The first one consists of a thick steel plate in contact with the upper part of the specimen (Fig. 2a). The striker impacts on the crushing plate on the top of the fixture, that transmits the load to the specimen.

In the second configuration, the upper plate is removed, and the striker's hemispherical head is substituted by a special insert with shape of a flat disk that hits the upper part of the specimen (Fig. 2b).

The fixture allows to test specimens with thicknesses from $1 \mathrm{~mm}$ to 10.

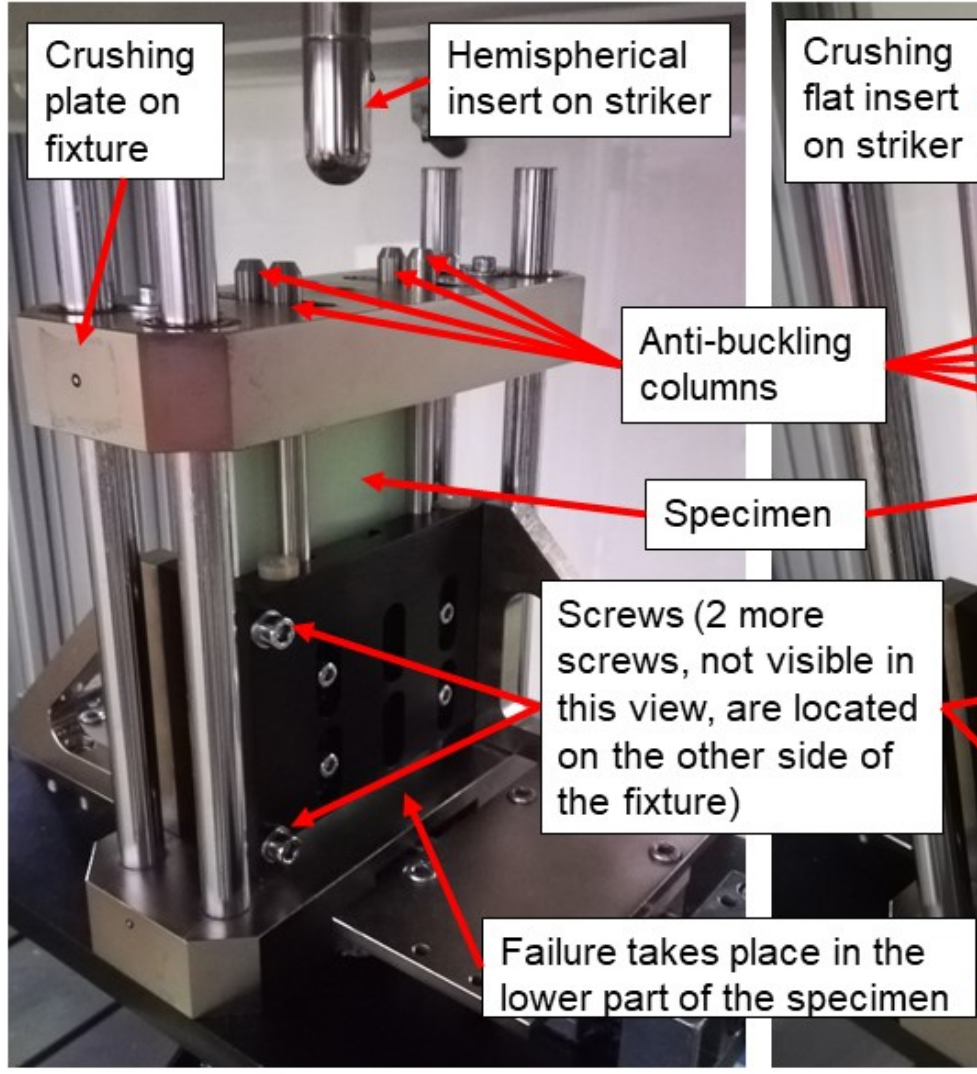

(a)

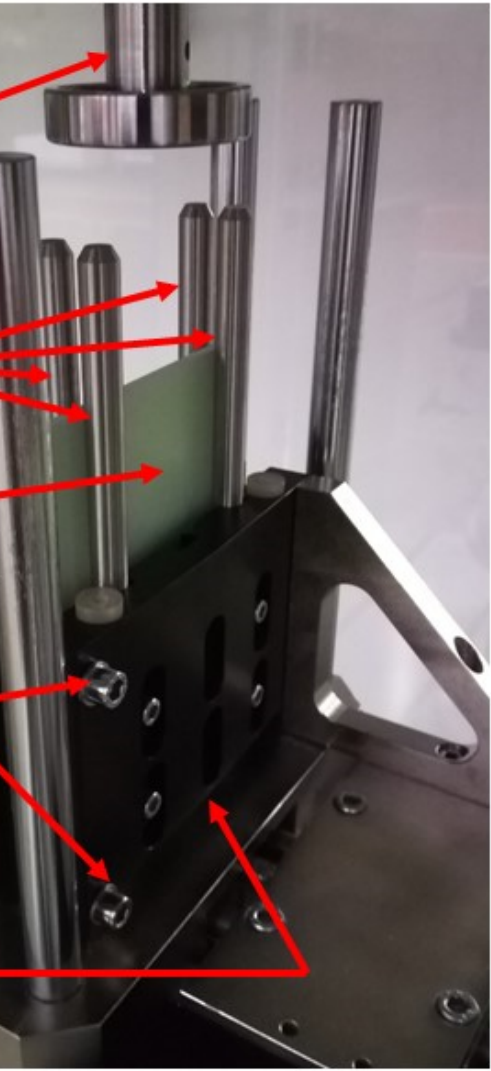

(b)

Figure 2: Fixture for crashworthiness test in two different configurations: (a) fixture with crushing plate on top, (b) fixture with crushing insert on the striker, and crushing plate removed.

\section{Methods}

The acquired data consists of a force-time curve: Fig. 3 shows two representative force versus displacement curves, obtained from force-time data with the testing fixture in the two different configurations described above (Fig. 2). 
The force-displacement curve is particularly useful to make comparisons between different materials and to calculate the Specific Energy Absorption (SEA). This curve can be divided in three parts.

The first part is related to the first contact between the falling mass and the specimen. When the crushing plate on the fixture is used (blue dash-dot curve in Fig. 3), the plot shows a high peak immediately followed by a part with null force, due to the inertia of the crushing plate and to the dynamic behavior of the system, as found also in literature [24]. When the crushing plate is removed (red solid curve in Fig. 3) and the dropped mass gets directly in contact with the specimen the initial peak disappears, leaving space for a smoother growth of the force in time with a lower peak, in agreement with the literature [20]. The oscillations of the signal in this part of the curve are evident and are due to the dynamics of the system, which is excited by the impact. The SEA calculated in the first part of curve is not correct because the acquired force cannot be referred to the cross section of the specimen because of the presence of the trigger, which is required to initiate the progressive crushing. The first part of curve is then discarded in the post-processing of results.

The second part of the curve is more stable and is characterized by the progressive crushing of the specimen. This part is not influenced by the trigger but can still have some oscillations that can be due to the dynamics of the system and to irregularities in the behavior of the material. The mean value of the force is a parameter that well characterizes the material, and consequently the Specific Energy Absorption can be calculated in a defined interval comprised by this part of curve.

The third portion of the curve, corresponding to the last few millimeters of displacement, is quite unstable and significantly rises the scatter of the results. The last millimeters of displacement of the striker are characterized by a drop of the force signal due to the interruption of the movement at the complete absorption of the kinetic energy of the falling mass. It is possible to notice a decrease of the displacement value due to the rebound of the impactor caused by the release of the elastic energy of the undamaged part of the specimen. This part of curve is discarded for SEA computation.

To verify the effectiveness of the testing procedure, the accuracy of the calculated displacement has been verified in two ways.

First, the final calculated displacement has been compared with the one measured on the crushed specimen at the end of the test (Fig. 4). Second, the whole displacement-time curve has been compared with the one obtained by image tracking from a high-speed video recorded during the crash event (Fig. 5). Since the displacement is obtained from the double integration of the force signal in time, good agreement of the two different displacement signals implies that force signal is correct. The high-speed video is also important to verify if the failure mode of the specimen is the desired one.

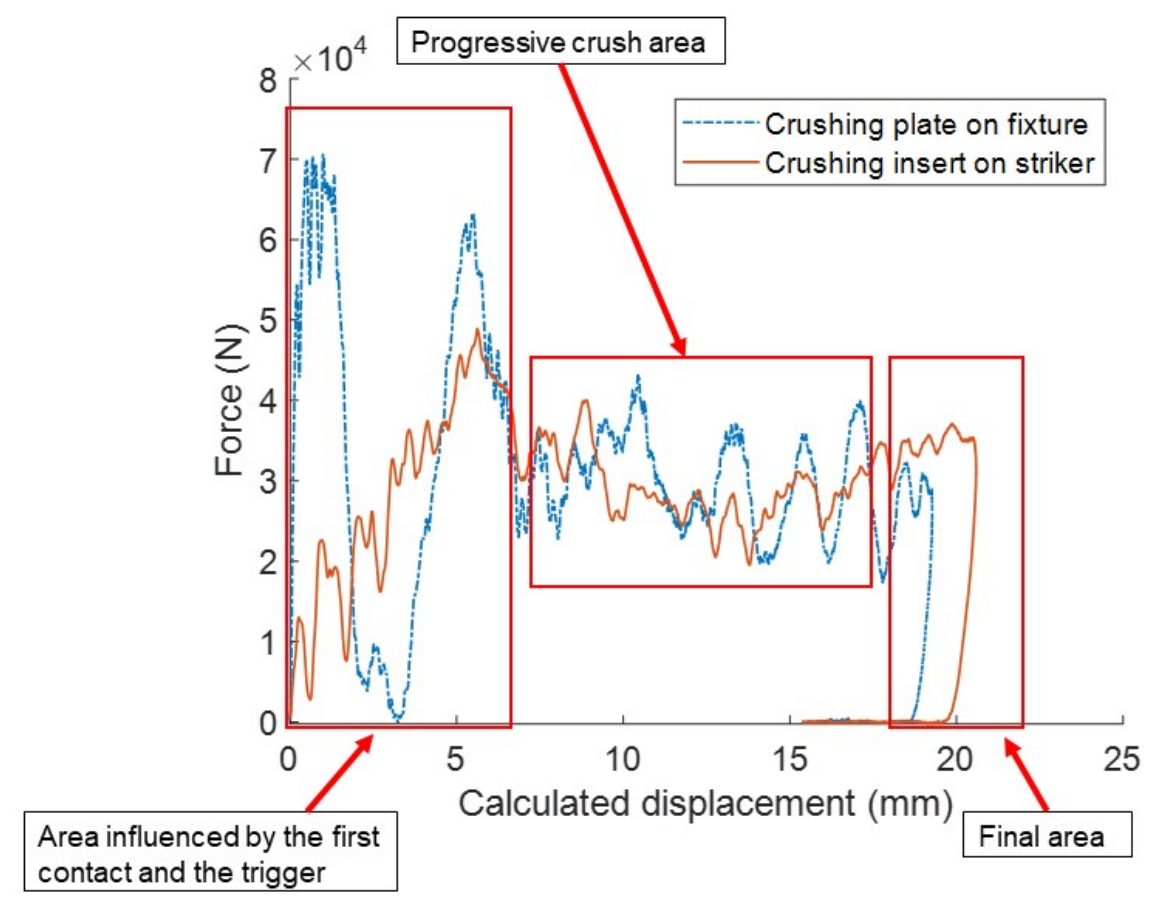

Figure 3: Comparison between results obtained in the configuration with crushing plate on the fixture (blue dash-dot curve) and with crush insert on the striker (red solid curve) during a test with impact energy of $600 \mathrm{~J}$ and dropped mass of $60.2 \mathrm{~kg}$. 


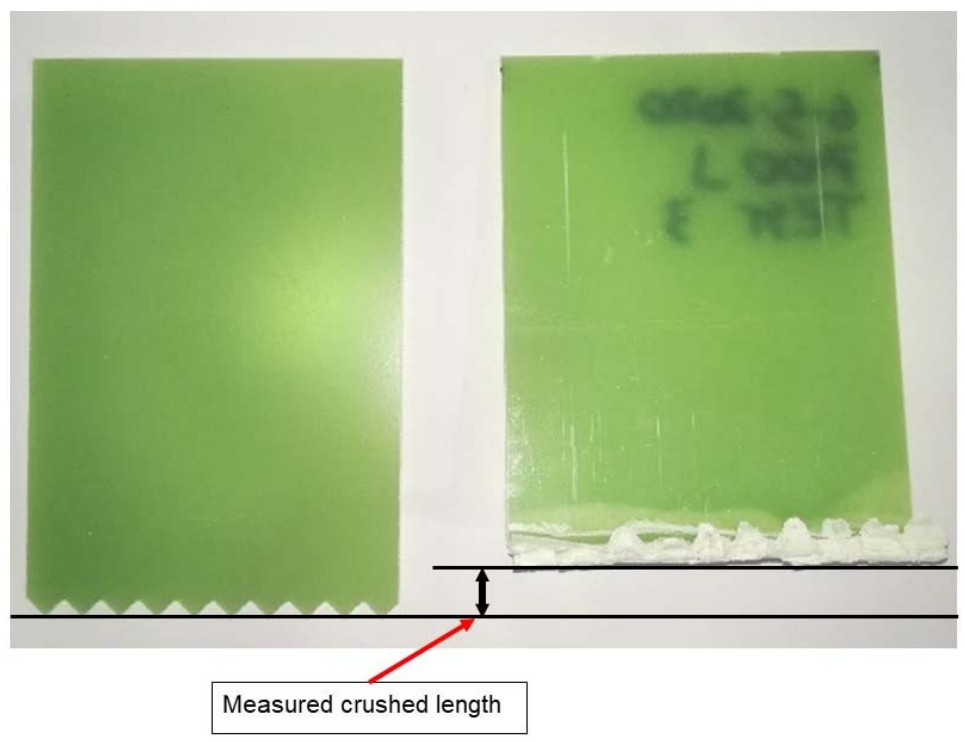

Figure 4: Measurement of the crushed length of a specimen after the test.

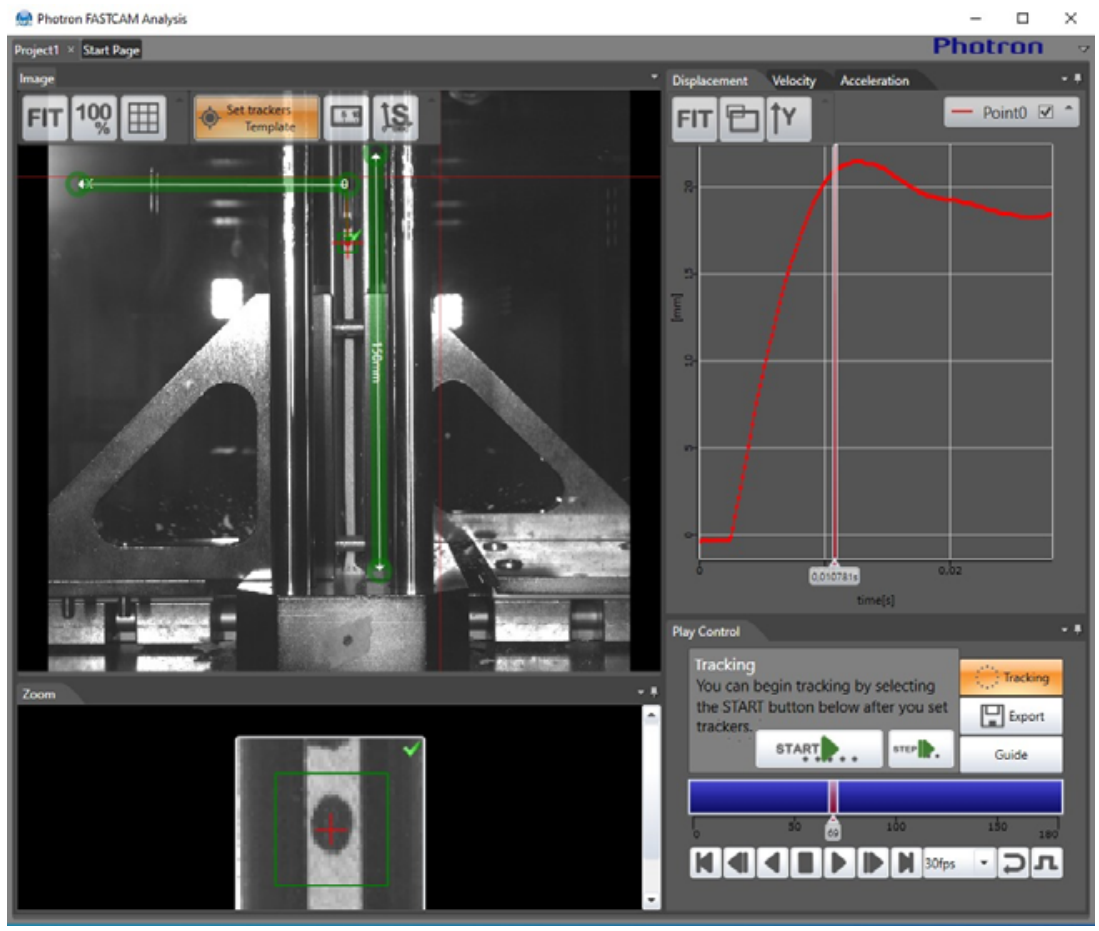

Figure 5: Tracking of the displacement of the specimen during the crush test from the high-speed video using the Photron PFA software.

\section{EXPERIMENTAL RESULTS}

7 he specimens tested showed a failure mode in line with expectations. The trigger caused the initiation of the failure in the lower part of the specimen, and failure observed after the test consists of two large foils in the lower part of the specimen with the addition of a high quantity of debris of smaller dimensions originated during the crush (Fig.

6).

Even though both testing configurations (i.e. crushing plate on fixture and crushing insert on striker) gave good results in terms of failure mode, the curves obtained with the crushing insert on the striker are preferred because they are more similar to those obtained in quasi-static tests reported in literature $[4,19,29]$. 
Observing the high-speed videos and focusing on the area where the failure takes place, it is possible to observe several failure modes in different moments of the same test or in different tests. The material shows a good crush behavior with a relatively high energy absorption, but the failure mode is not constant during the test. Delamination, fragmentation and local buckling of some layers are visible in different areas of the failure and in different moments of the same test as shown in Fig. 7. This is probably one of the causes of the oscillations in the force signal (Fig. 3), given that different failure modes have been observed to absorb different amounts of energy [4].

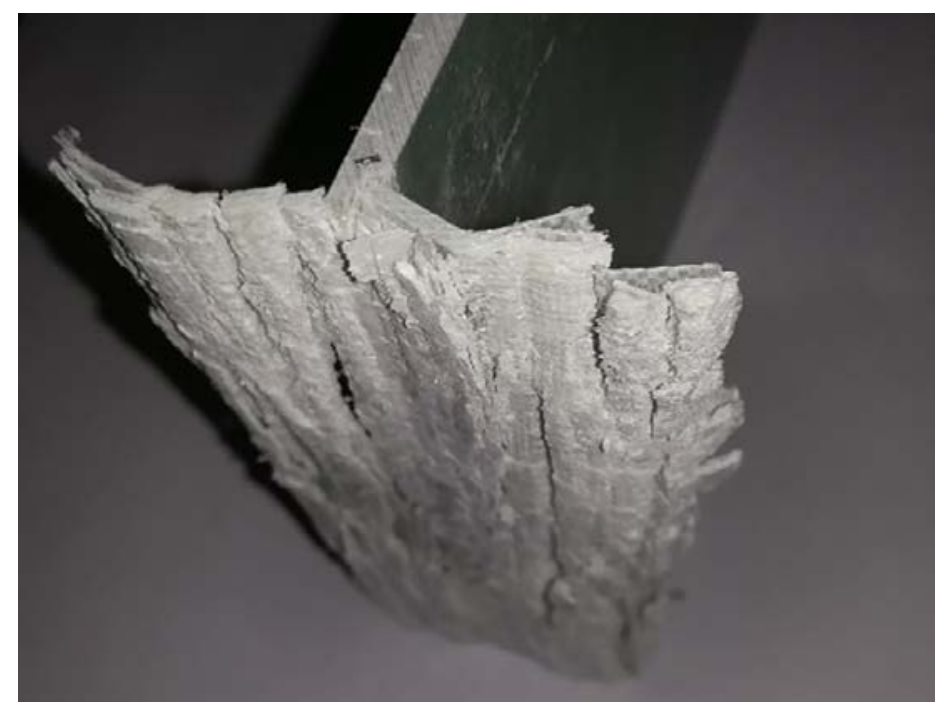

Figure 6: Detail of the crushed part of a glass fiber specimen

As visible in Fig. 7, delamination of the layers that compose the material is the most evident failure mechanism, but not the only one. The superficial layers sometimes show buckling in some points while bending toward the outside of the support, while the central layers alternate phases of buckling, bending and fragmentation. Several fragments are found after the test, showing that the fragmentation of both matrix and fibers occurs during the test. The dimensions of the fragments vary from barely visible dust to fragments of laminate with dimensions of some centimeters, with the addition of the two large foils in Fig. 6.

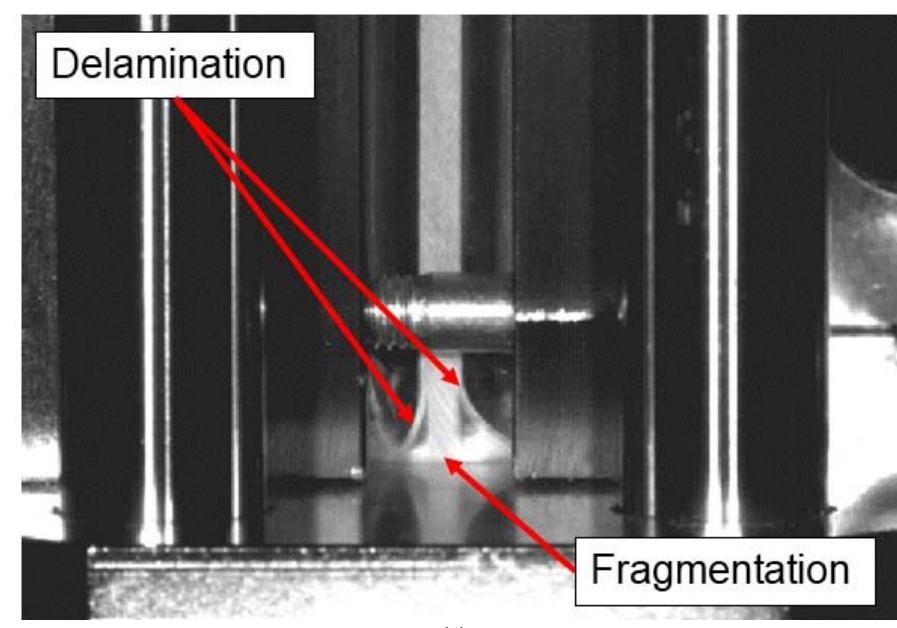

(a)

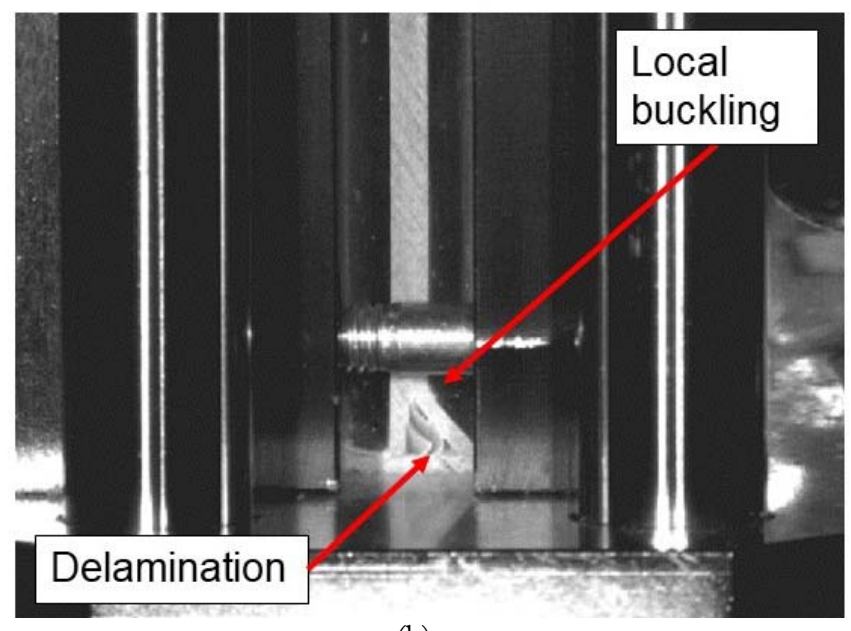

(b)

Figure 7: Identification of the failure modes in different moments of the same test on glass fiber specimens, as recorded through the highspeed camera at the beginning of the test (a) and at the end of the test (b). The failure mode is a combination of splaying, fragmentation and local buckling. 


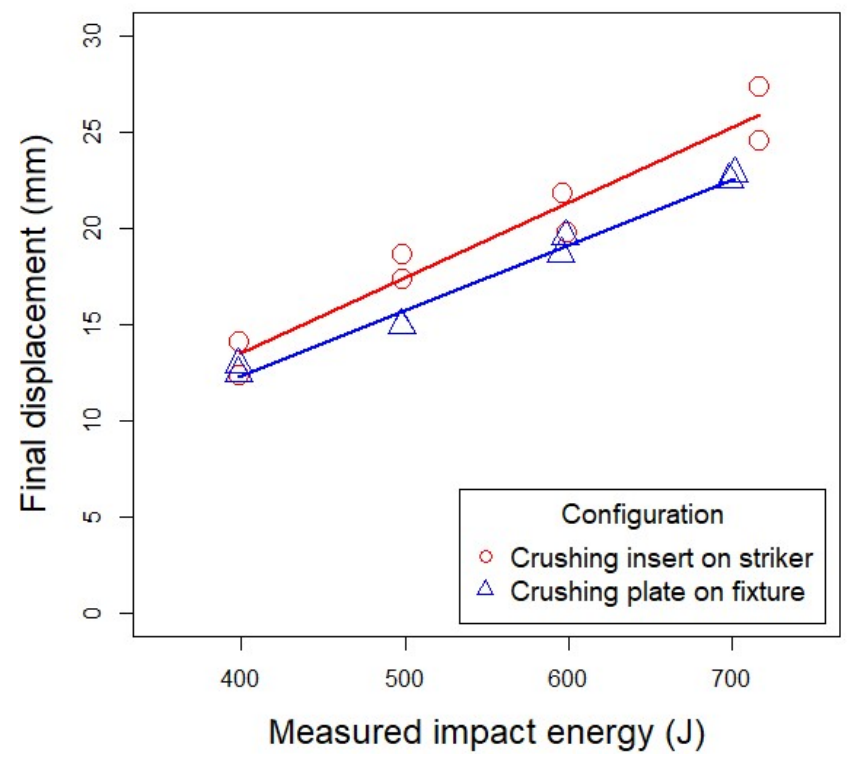

Figure 8: Linear correlation between impact energy and final crushed displacement calculated from the acquired force data.

\begin{tabular}{|c|c|c|c|}
\hline & & Crushing plate on fixture & Crushing insert on striker \\
\hline \multirow{2}{*}{ Slope } & Estimated coefficient & 0.031766 & 0.0353961 \\
\hline & P-value & $8.42 \mathrm{e}-12$ & $8.27 \mathrm{e}-10$ \\
\hline \multirow{4}{*}{ Other regression results } & Multiple $\mathrm{R}^{2}$ & 0.999 & 0.9964 \\
\hline & Adjusted $\mathrm{R}^{2}$ & 0.9989 & 0.9959 \\
\hline & F-statistic & 7174 & 1930 \\
\hline & P-value & $8.419 \mathrm{e}-12$ & $8.272 \mathrm{e}-10$ \\
\hline
\end{tabular}

Table 2: Regression results for the two linear models with null intercept plotted in Fig. 8, where the final displacement is expressed as a function of the impact energy.

The test results show a linear increase of the final displacement at the end of the test with respect to the impact energy (Fig. 8). Two linear models, one for each testing configuration, were estimated with software $\mathrm{R}$ (Tab. 2). The behavior of the two testing configurations is similar, with the crushing plate on the fixture responsible of a slightly lower displacement at the end of the test, probably due to the friction between the crushing plate and its guiding columns, that dissipates a part of the kinetic energy.

A linear dependence between the impact energy and the volume of crushed material indicates that the SEA of this material is not depending on the impact energy, and consequently on the impact velocity because the falling mass was kept constant during these tests. At a first glance this could disagree from what is shown in Fig. 9, that reports that the SEA as a function of the impact energy is not constant.

However, the SEA reported in Fig. 9 does not take in account the full test, but only the central part of the force-displacement curve (between $40 \%$ and $90 \%$ of the final displacement of each test), where the crash behavior of the material has been observed to be more stable. The increase of the impact energy (and velocity) seems then to determine a decrease of the specific energy absorption of the material in both testing configurations (i.e. crushing plate on the fixture and crushing insert on the striker).

The decreasing behavior of the SEA can be explained by taking into account the segment of the force-displacement curve that has been considered for the SEA computation. In high-energy impacts the segment completely falls in the part of curve that shows a plateau. On the other hand, in low-energy impacts the segment falls in the region that shows a peak, causing 
higher values of SEA. Therefore, for the investigated material, only tests carried out at impact energies equal or higher than $600 \mathrm{~J}$ provide a correct SEA value, related to steady crush conditions.

The peak force, instead, has very different behaviors in the two testing configurations (Fig. 10). The crushing plate on the top of the specimen causes high peak forces whose values increase with the impact speed. On the other hand, peak forces are lower and constant with the crushing insert on the striker. This is also confirmed by the two regression models implemented in $\mathrm{R}$ for the two testing configurations (Tab. 3).

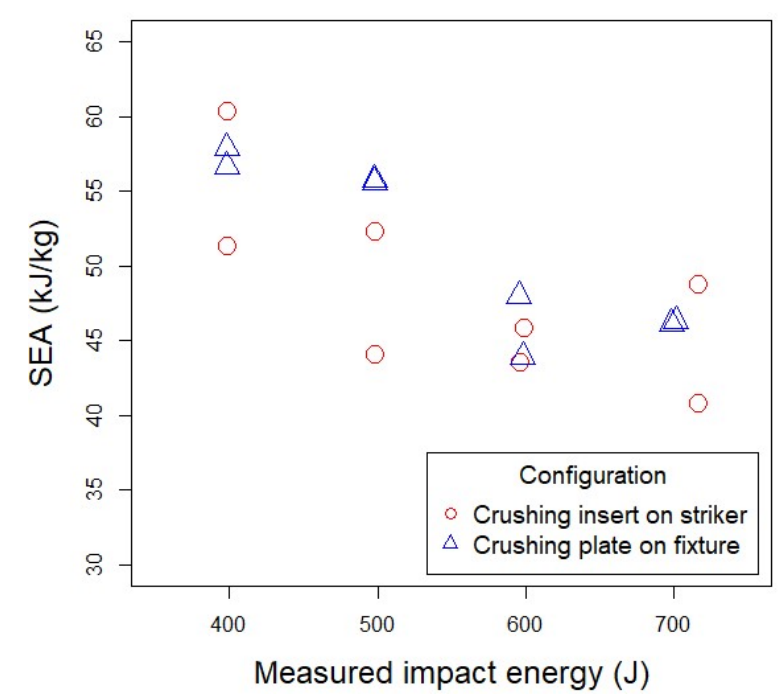

Figure 9: Specific Energy Absorption of the material as a function of the impact energy at constant falling mass of $60.2 \mathrm{~kg}$.

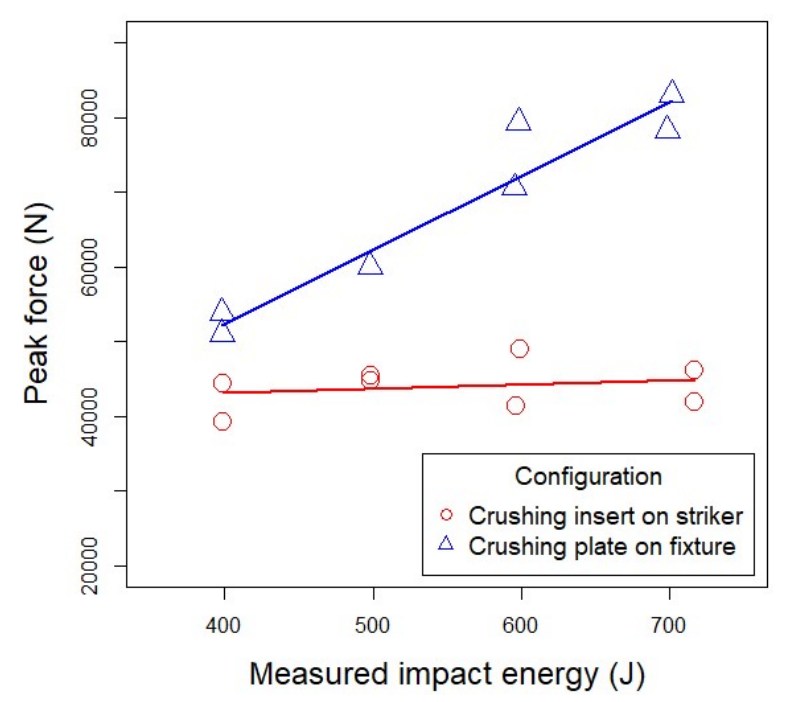

Figure 10: Peak force during the test as a function of the impact energy with constant falling mass of $60.2 \mathrm{~kg}$.

\begin{tabular}{|c|c|c|c|}
\hline & & Crushing plate on fixture & Crushing insert on striker \\
\hline \multirow{2}{*}{ Slope } & Estimated coefficient & 99.29 & 5.973 \\
\hline & P-value & 0.000148 & 0.559017 \\
\hline \multirow{2}{*}{ Intercept } & Estimated coefficient & 12582.93 & 40671.419 \\
\hline & P-value & 0.103480 & 0.000303 \\
\hline \multirow{4}{*}{ Other regression results } & Multiple $\mathrm{R}^{2}$ & 0.9229 & 0.05992 \\
\hline & Adjusted $\mathrm{R}^{2}$ & 0.91 & -0.09675 \\
\hline & F-statistic & 71.79 & 0.3825 \\
\hline & $\mathrm{P}$-value & 0.0001478 & 0.559 \\
\hline
\end{tabular}

Table 3: Regression results for the two linear models plotted in Fig. 10, where the peak force is expressed as a function of the impact energy.

\section{CONCLUSIONS}

\footnotetext{
new testing procedure to measure the crashworthiness of composite materials has been proposed. The procedure A is based on impact tests of flat coupons of material, using a drop weight testing machine, and requires a device to hold the specimen and avoid buckling during the impact. The crush force is measured during the test and allows to calculate the value of Specific Energy Absorption (SEA) of the material, that characterizes the behavior of the material during a crash.
} 
Several tests have been carried out with different impact energies, obtaining a linear correlation between the impact energy and the final crushed length of the specimen. The test setup worked well with glass fiber-epoxy specimens, obtaining an average value of SEA between $40 \mathrm{~kJ} / \mathrm{kg}$ and $60 \mathrm{~kJ} / \mathrm{kg}$, that decreases with impact energy. The high speed video recorded during the test showed the failure of the specimen, that appeared to be a complex mixture of foiling, local buckling and fragmentation. This points out the need of further investigation on the relationship between material, failure modes and crush energy absorption.

Of the two testing configurations proposed, the one with crushing insert on the striker seems to be the most useful because it reduces the dynamic effects given by the testing equipment and provides a more accurate force acquisition during the full test.

The testing procedure demonstrated to be useful for the experimental evaluation of the crush force and SEA of flat specimens, but further investigation is necessary to compare the results with other testing methods and specimen geometries. Tests are also necessary to verify the applicability of the presented testing procedure to other materials. In addition, further investigation is required to assess the possibility to use the acquired results as input data for FEM simulations.

\section{REFERENCES}

[1] Feraboli, P., Deleo, F., Garattoni, F. (2007). Efforts in the standardization of composite materials crashworthiness energy absorption, Am. Soc. Compos. 22nd Tech. Conf. Am. Soc. Compos. 2007 - Compos. Enabling a New Era Civ. Aviat., 1, pp. 741-759.

[2] CMH-17. (2012).Crashworthiness and Energy Management. Composite Materials Handbook (CMH-17), vol. 3.

[3] Lukaszewicz, D.H. -J. A. (2013). Automotive Composite Structures for Crashworthiness. In: Elmarakbi, A. (Ed.), Advanced Composite Materials for Automotive Applications: Structural Integrity and Crashworthiness, Chichester, UK, John Wiley \& Sons, Ltd, pp. 99-127.

[4] Farley, G.L., Jones, R.M. (1989). Energy-Absorption Cabability of Composite Tubes and Beams. NASA Technical Memorandum 101634.

[5] Hull, D. (1991). A Unified Approach to Progressive Crushing of Fibre-Reinforced Composite Tubes, Compos. Sci Technol., 40, pp. 377-421.

[6] Bisagni, C., Di, G., Fraschini, L., Terletti, D. (2005). Progressive crushing of fiber-reinforced composite structural components of a Formula One racing car, 68, pp. 491-503, DOI: 10.1016/j.compstruct.2004.04.015.

[7] Obradovic, J., Boria, S., Belingardi, G. (2012). Lightweight design and crash analysis of composite frontal impact energy absorbing structures, Compos. Struct., 94(2), pp. 423-430, DOI: 10.1016/j.compstruct.2011.08.005.

[8] Joosten, M.W., Dutton, S., Kelly, D., Thomson, R. (2011). Experimental and numerical investigation of the crushing response of an open section composite energy absorbing element, Compos. Struct., 93(2), pp. 682-689, DOI: $10.1016 /$ j.compstruct.2010.08.011.

[9] Liu, Z., Xia, Y. (2019). Development of a numerical material model for axial crushing mechanical characterization of woven CFRP composites, Compos. Struct., 230(July), pp. 111531, DOI: 10.1016/j.compstruct.2019.111531.

[10] Dalli, D., Varandas, L.F., Catalanotti, G., Foster, S., Falzon, B.G. (2020). Assessing the current modelling approach for predicting the crashworthiness of Formula One composite structures, Compos. Part B Eng.,

DOI: 10.1016/j.compositesb.2020.108242.

[11] (2018). ASTM D3763 - 18: Standard Test Method for High Speed Puncture Properties of Plastics Using Load and Displacement Sensors.

[12] (2018). ASTM D5628 - 18: Standard Test Method for Impact Resistance of Flat, Rigid Plastic Specimens by Means of a Falling Dart (Tup or Falling Mass).

[13] (2000). ISO 6603-1: Plastics - Determination of puncture impact behaviour of rigid plastics - Part 1 : Non-instrumented impact testing.

[14] (2000). ISO 6603-2: Plastics — Determination of puncture impact behaviour of rigid plastics — Part 2: Instrumented puncture testing.

[15] (2015). ASTM D7136/D7136M - 15: Standard Test Method for Measuring the Damage Resistance of a FiberReinforced Polymer Matrix Composite to a Drop-Weight Impact Event.

[16] (2017). ASTM D7137/D7137M - 17: Standard Test Method for Compressive Residual Strength Properties of Damaged Polymer Matrix Composite Plates.

[17] (2009). ISO 18352:2009 Carbon-fibre-reinforced plastics — Determination of impact properties at a specified impactenergy level. 
[18] Lavoie, J.A., Morton, J. (1993). Design and Application of a Quasistatic Crush Test Fixture for Investigating Scale Effects in Energy Absorbing Composite Plates. NASA Contractor Report 4526.

[19] Feraboli, P. (2009). Development of a Modified Flat-plate Test Specimen and Fixture for Composite, J. Compos. Mater., 43(19), pp. 1967-1990, DOI: 10.1177/0021998309343025.

[20] Feraboli, P., Wade, B., Deleo, F., Rassaian, M. (2009). Composites: Part A Crush energy absorption of composite channel section specimens, Compos. Part A, 40(8), pp. 1248-1256, DOI: 10.1016/j.compositesa.2009.05.021.

[21] Lescheticky, J., Barnes, G., Schrank, M. (2013). System level design simulation to predict passive safety performance for CFRP automotive structures, SAE Tech. Pap., 2, DOI: 10.4271/2013-01-0663.

[22] Aitharaju, V., Kia, H.G., Aashat, S., Pulugurtha, V.C. (2016). Modeling of Crush Behavior of Carbon Fiber Composites, Proc. Am. Soc. Compos. - Thirty-First Tech. Conf.

[23] Israr, H.A., Rivallant, S., Bouvet, C., Barrau, J.J. (2014). Finite element simulation of $0^{\circ} / 90^{\circ}$ CFRP laminated plates subjected to crushing using a free-face-crushing concept, Compos. Part A, 62(July), pp. 16-25, DOI: https://doi.org/10.1016/j.compositesa.2014.03.014.

[24] Duong, A.V., Rivallant, S., Barrau, J.J., Petiot, C., Malherbe, B.Î. (2010).Influence of speed on the crushing behavior of composite plates. 7th Asian-Australasian Conference on Composite Materials 2010, ACCM 2010, 1, pp. 678-681.

[25] Ueda, M., Nishimura, T. (2010). Compressive failure of unidirectional CFRP plate under progressive crushing, 25th Tech. Conf. Am. Soc. Compos. 14th US-Japan Conf. Compos. Mater., 2, pp. 1658-1668.

[26] Cauchi Savona, S., Hogg, P.J. (2006). Effect of fracture toughness properties on the crushing of flat composite plates, Compos. Sci. Technol., 66(13), pp. 2317-2328, DOI: 10.1016/j.compscitech.2005.11.038.

[27] National Electrical Manufacturers Association. (1998). NEMA LI-1-1998 (R2011): Industrial Laminated Thermosetting Products.

[28] Demezzi SAS. Vetro epossidico NEMA FR4. Available at: http://www.demezzi.it/termici/fr4.php. [accessed October 13, 2020].

[29] Carruthers, J.J., Kettle, A.P., Robinson, A.M. (1998). Energy absorption capability and crashworthiness of composite material structures: A review, Appl. Mech. Rev., 51(10), pp. 635-649, DOI: 10.1115/1.3100758. 